\title{
THE BRITISH JOURNAL OF VENEREAL DISEASES
}

\section{DISCUSSION ON THE PRECEDING PAPER}

Brig. Osmond (the President) expressed the Society's gratitude to Dr. Erskine for his paper, which certainly contained some salutary warnings and was somewhat provocative. On what evidence did he found his statement that sulphonamide administration ought to be continued day and night? It had certainly been the experience in the Army that it did not matter very much, provided that a fairly big dose was given last thing at night and first thing in the morning. If there were evidence that the administration should be continued during the night, he would like to know what it was. The next controversial point was the use of vaccines between the first and second course of sulphonamides. Was their action specific or non-specific? What were the doses ? Was there any pathological evidence that the giving of these vaccines increased the amount of antibody?

He agreed entirely with Dr. Erskine in his very suitable warning about the dosage of mapharside. He himself had always maintained that mapharside was not ten times as effective as neoarsphenamine, and the more that was stressed the more likely were cases to be treated adequately when mapharside was used as the arsenical.

Maj. D. I. Williams said that, whereas there were many points on which he could agree with Dr. Erskine, he would confine himself to those on which he could not. He thought that most people now considered that thiosulphate was of no value in the treatment of complications arising from arsenotherapy. He had never found it of any use and biochemically there was no foundation for the belief in its value. He was a firm believer in an infective agent as the cause of jaundice during arsenotherapy. In the Army the incidence of jaundice had dropped strikingly since the routine boiling of syringes had been introduced ; figures worked out at Netley confirmed the theory of infective causation and also showed that the use of mapharside did not reduce the incidence of jaundice. The infective agent was carried equally well whatever vehicle it was in, and when mapharside was given twice a week there was a double chance of syringe transference of infection.

The paper by Beattie and Marshall, to which Dr. Erskine had referred, presented no convincing evidence that the time of incidence of jaundice could be delayed by the amino-acids which they gave to their patients. The time of incidence was spread over such a long period and their cases were so few that their results did not bear statistical analysis.

The next point was the question of the action to be taken when the results of a routine Kahn or Wassermann test were found repeatedly to be positive. The first step was, surely, the examination of the cerebrospinal fluid. Some of these cases would in time provide clinical evidence of syphilis. There was no doubt in his mind that, with few exceptions, treatment ought not to be withheld.

Maj. Williams quite agreed with a dosage of sulphonamide at about the level suggested by Dr. Erskine ; to give it 3 times in the day at 8-hourly intervals seemed to be most satisfactory. There seemed now to be no place for sulphapyridine in the treatment of gonorrhoea. It was unusual for sulphapyridine to succeed where sulphathiazole had failed, and a second course of sulphathiazole was just as likely, if not more likely, to bring success. There was only conflicting evidence as to the relation of the blood level of sulphonamide to resistance. He thought that a gonococcal vaccine had a non-specific effect and that equally effective, if not better, results could be obtained by using another form of protein therapy.

Non-specific urethritis was an increasing and even a man-power problem. He had been brought up in a school of venereology which thought that most of these cases were due to the gonococcus. Similarly, whereas post-gonococcal urethritis was attributed by many observers to secondary invaders, it was surprising how the gonococcus would reappear during treatment, often after an interval of time, in cases in which the clinical picture was the same as in those cases in which it was not found.

Lt.-col. A. J. King said that Dr. Erskine had spoken of the fact that the former pessimistic attitude to the treatment of gonorrhoea had given way to optimism. Perhaps it would be more accurate to speak of over-optimism. Early reports about the value of penicillin greatly resembled those about the sulphonamides, when they were first introduced. If underdosage of penicillin was used and if afterwards the cases were not assessed as to cure with adequate care, this new and potent remedy might prove to be no more than a short cut to latency.

Dr. Erskine had mentioned the stigma attached to venereal disease and the importance of education in the right outlook on this subject. Some of the worst offenders were in the medical and nursing professions - a point which had greatly handicapped progress in the subject of venereology. Doctors and nurses must be educated properly before the influence of their outlook could be brought to bear usefully on the general public.

As regards the organization of venereal diseases clinics, a point to stress was that up-to-date methods in the treatment of venereal infections could not be used satisfactorily in the ad hoc clinic. An adequate number of beds should be available and specialists in the subject should have full access to them.

Dr. Erskine had stressed the importance of close clinical observation of patients treated by the newer remedies. Superficially it might seem that the treatment of venereal disease was now quick and easy and did not require special experience. On the contrary, the necessity for close observation and experience remained imperative and this was certainly no time for relaxation of standards. 


\section{VENEREAL DISEASE PATIENT}

On the subject of the treatment of resistant cases by the giving of vaccines and of the use of a different sulphonamide preparation after a 10-day interval, he would suggest to Dr. Erskine that time was usually the important factor in the treatment of sueh cases, and that he would probably get just as good results by waiting the 10 days, or a little more, without using vaccines and without changing the drug.

Dr. Erskine had said that penicillin was not of much value in the treatment of non-specific urethritis, but Lt.-col. King had found it effective in some cases, although not in as large a proportion as in the treatment of gonorrhoea. The number of his cases treated in this way was, however, small, and he was not in a position to emphasize that point very strongly.

Finally, on the question of post-arsphenamine jaundice, he wished to add his opinion that Dr. Erskine's impressions were unconvincing evidence to put against the well controlled investigation that had been carried out at Netley, which strongly supported the view that there was a transmission of infection by syringes. There was also the fact which Maj. Williams had mentioned, that since the routine of sterilization of syringes had been reviewed in the Army there had been a striking and progressive decline in the incidence of post-arsphenamine jaundice in its hospitals.

Maj. S. M. Laird said that Dr. Erskine's paper was a complete and masterly account of most of the difficulties which were experienced in venereal disease practice, both civil and, to a large extent, military as well. There were many points on which he agreed with Dr. Erskine, particularly in regard to his general remarks on sulphonamide dosage in gonorrhoea and the value of irrigation as a routine.

With regard to the desirability-or the evidence for the desirability - of dosage throughout the 24 hours, probably at shorter intervals than 8 hours, he personally considered that this practice was desirable; but circumstances had forced him some 15 months ago to reduce his scheme to 4 sets of tablets given in the day-time hours, and he had not found any difference in the results. He would like to associate himself with Dr. Erskine in what he had said about the undesirability of indiscriminate arsenotherapy in cases of so-called Vincent's angina.

Coming to the points of disagreement, one had already been dealt with adequately by Col. King and Maj. Williams : the question of jaundice. In the last year he had been doing a little work on similar ines to the work done at Netley, and he now had a larger number of jaundiced cases than that quoted in the Netley report. He had come to regard jaundice as a complication of intravenous therapy and not as a complication of syphilis or of its treatment. The evidence which prevented Dr. Erskine from believing in the syringe transmission theory was interesting. The fact that, at a clinic in which military and civil patients were having treatment under apparently similar circumstances, the incidence in the military patients was higher than in the civil patients, was of interest. Maj. Laird had been in exactly similar circumstances himself at the time at which Col. Bigger published the article originally suggesting the hypothesis of syringe transmission and, like Dr. Erskine, he had used the same observation to support his belief, at that time, that jaundice was not due to syringe transmission. He had been converted since and would suggest, without knowledge of local conditions, that a possible explanation was that Dr. Erskine's own syringe technique was of a high standard, that his military cases were transferred rapidly from one clinic to another and that they were infected not at Dr. Erskine's clinic but before arriving there; furthermore, that because his own technique was good he did not pass on the infection from the military patients to the civil patients.

Finally, Maj. Laird took the opportunity of expressing his feeling that there had been for quite a long time almost a campaign of suggestion that, unless the medical services in the Forces were very careful, there would be a tremendous wave of venereal disease produced amongst the civil population by the demobilization or discharge from the Forces of men who were suffering from venereal disease and who had not been adequately treated. For the last 12 months he had been seeing men returning from overseas who had been infected on disembarkation leave ; the problem was thus not one-sided. There were indeed two sides, and his own fear was not for the civil population but for the Servicemen returning to their homes and to civil life.

Col. I. W. Harrison said that many times during Dr. Erskine's paper he had found himself saying, "I told you so". He wished to endorse what Dr. Erskine had said about venereology being the Cinderella of the specialities. There were one or two points raised by Dr. Erskine which Col. Harrison was perhaps in a more favourable position to answer than were most people. One was his mention of the difficulties of the one-man clinic, run by a medical officer only partly trained, in an isolated place with no supervision. This was a more difficult problem than one might imagine at first. In the Venereal Diseases Scheme it was necessary to bring the diagnosis and treatment as close to the patient as possible. Good well-trained specialists were not distributed as widely as it was necessary to distribute the clinics. The average medical man was rather resentful of supervision and the difficulty was to get the half-trained man to submit to it. For a clinic situated 50 miles from a town in which there were specialists, it was difficult to get the specialist to go so far three times or even once a week. These practical difficulties must be taken into account when the efficiency of the Venereal Diseases Scheme was assessed. The only thing that could be done was to get some reasonable routine understood and adopted by the people who had not much time to study the subject intensively, and that was what the Ministry of Health had been trying to do ever since the scheme was commenced.

Dr. Erskine had suggested that non-gonococcal urethritis, and perhaps non-gonococcal vaginitis, should be the responsibility of the public health authorities. To make the care of 


\section{THE BRITISH JOURNAL OF VENEREAL DISEASES}

these other diseases the official responsibility of the public health authorities would require a re-casting of the Venereal Diseases Regulations, and, although the revision of these regulations was long overdue, the problem was how to get it done. It was a very controversic l subject and in any case new legislation was very difficult to introduce. Everyone in the meeting knew, however, that unofficially women were tree ted for trichomonas vaginitis in the public clinics and that nothing was said about it, although officially they should be referred to some other department of the hospital. Non-gonococcal urethritis and other forms of urethritis also were treated in the public clinics with the full sympathy of the Ministry of Health.

Adverting to a point made by Col. King regarding ad hoc clinics, Col. Harrison said that there were two sides to that question. There had been many cases in which a change-over to an ad hoc clinic had brought about a tremendous improvement in the efficiency of the local venereal diseases treatment arrangements. There were cases in which the local hospitals had not " played the game" and the rublic health authority had been driven to establish an ad hoc clinic. At the very beginning of the scheme the chief hospital in one large city in Great Britain absolutely refused to have anything to do with this branch of Medicine, so the local authority set up an ad hoc clinic and for the next few years the second largest attendances in the country were at that clinic. Therefore, given good conditions, the ad hoc clinic could be a very efficient place and could in certain circumstances be far more efficient than the hospital clinic.

On the subject of non-gonococcal urethritis, he would suggest that a certain number of cases were due to mechanical irritation by salts precipitated in the urine. He had in mind a number of cases in which the urethritis was due to phosphates and he knew of a case due to very numerous crystals of calcium oxalate. As a matter of routine the urine deposit ought always to be examined in a fresh state in all these cases, because there might be found the cause of the urethritis.

With regard to the question of jaundice, Col. Harrison was much interested in the explanation given by Col. King, which agreed with certain ideas which he himself had formed. He hoped that they would stand the test of time.

He was glad to hear what had been said about the relative toxicity and therapeutic efficacy of arsenoxide. For a long time he had contended that it was not 10 times as effective as neoarsphenamine and, as long as statements conveying that impression continued to be advertised, the routine use of arsenoxide would not receive any encouragement from him. In regard to its toxicity, a recent investigation which he had made showed that the incidence of jaundice in cases treated with arsenoxide was, if anything, slightly higher than that in cases treated with neoarsphenamine. The ratio of jaundice to numbers of injections was also higher, although the average individual dose of arsenoxide was no more than one-tenth the average individual dose of neoarsphenamine.

Lt.-col. King referred again to the question of the ad hoc clinic. He did not suggest that excellent work had not been done in these clinics, but the point he was trying to make was that the ad hoc clinic was not more than a temporary and relatively unsatisfactory means of closing a gap. A clinic, to be efficient, did require beds.

Dr. Letitia Fairfield said that she was delighted to hear Dr. Erskine mention the importance of obtaining beds. She thought that she was speaking to the converted in this matter, because there must be many who had had the recent experience of a wider use of beds and knew the advantage obtained thereby. Very extensive planning was being undertaken by the authorities and there would be a good deal of competition for beds; unless the venereal diseases point of view was pressed now, she was afraid that their claim would be squeezed out altogether. Outside the Society there was not the least conception of the importance and necessity for a generous use of hospital beds in the modern treatment of venereal disease.

The next point to which she wished to refer was that of the interesting remarks let fall by Dr. Erskine on the subject of compulsion. Although the objections to notification were disappearing to a certain extent, she still felt that, on account of the long term needed for the treatment of venereal disease and the uncertainty of diagnosis, notification would create more difficulties than it would solve. Many members of the profession who gave lip service to the idea of notification would be the first to object to the compulsion necessary in order to carry it out. If notification were instituted at all, there would have to be a great deal more interference between doctor and patient than the Ministry of Health had suggested, and Dr. Erskine's approach to that important aspect of dealing with venereal diseases ought to be welcomed.

Col. Harrison referred to Dr. Fairfield's mention of the case for beds. The endeavour to treat as many cases with penicillin as possible would bring home to medical officers of health the need for more beds than they had at present.

With regard to congenital syphilis, he did not believe that there would be anything like so much of it after the present war as after the war of 1914-1918, during which the mortality of infants certified as being due to syphilis reached a peak in 1917 of 2.03 per 1,000 live births, after having been 1.2 in 1913. This would give a fair idea of the increase of syphilis in wómen. A similar increase was not occurring during the present war. The last figure he had seen under that heading was one-tenth of the 1917 figure, namely, 0.2, and for that reason he was optimistic with regard to the incidence of congenital syphilis after the present war. Women suffering from syphilis were much better treated than they had been during the war of 1914-1918.

Dr. Mascall said that there were one or two suggestions which he would like to make. Nonspecific urethritis had always been a nuisance and its incidence had increased definitely since the present war began; this, he would suggest, was due to our failure to demonstrate the 


\section{VENEREAL DISEASE PATIENT}

gonococcus. That might be because culture media had deteriorated considerably during the war. Nobody could be blamed for it, as pathologists were unable to obtain satisfactory ingredients for keeping up the standard of the media.

With regard to false positive Wassermann reactions, he was not at all convinced that the fault did not lie in the laboratories. The staffs had been grossly overworked and much had of necessity been left to the technicians. The false positives were due not so much to the patients as to the laboratory technique, and he thought that when more and better pathologists were available the number of false positives would decrease.

There was perhaps not enough investigation of non-specific infections carried out. During his recent investigations of Trichomonas vaginalis, he obtained 2 positives in 100 male cases, which was a fairly high percentage. It showed that this organism should not be forgotten in dealing with-non-specific urethritis in the male.

Two of the most difficult problems, in his opinion, were first, that of the patient who attended the clinic after having received some tablets of unknown type, and who still had a discharge, and secondly, the man who had had intensive treatment for syphilis and still had a positive Wassermann reaction. How long ought we to wait for that Wassermann reaction to become negative, and what was happening during that waiting period ? Was the patient merely transforming himself into a latent syphilitic ? If so, the treatment required a considerable amount of alteration.

Dr. Erskine (in reply) said, with regard to the President's reference to the day and night administration of sulphonamides, that, in his experience, the cessation of treatment during the night gave less satisfactory results; this was certainly so when the patients were in wards in which the routine was not followed. Out-patients whose condition failed to improve were usually those who admitted that the spacing of doses-had not been regular. When using sulphathiazole, he had originally tried 6-hourly spacing, prescribing 1 gramme for each dose ; this spacing was inconvenient and in a number of the cases it failed to control the infection; subsequently, he had changed the routine to 1.5 grammes every 8 hours, which appeared to interfere less with the patients' routine, and much better results had been obtained.

With regard to the gonococcal vaccine, he supposed that its effect was very largely non-specific. Perhaps the value of the gonococcal fixation test was debatable, but positive reactions were often obtained after the giving of small doses of the vaccine for a few weeks; the effect therefore might be of a specific nature. Probably the important thing was to fill up the interval before more sulphonamide treatment could be given, because of the psychological effect on the patient of having something done. He used 5 million mixed gonococcal organisms as the first dose of vaccine and every 5 days increased it by $2 \frac{1}{2}$ millions; the vaccine was given intradermally.

Maj. Williams had referred to the virus theory of post-arsphenamine jaundice. Dr. Erskine knew that in certain commands in the Army the hospitals had been privileged in having an ample supply of syringes. If Maj. Williams had been working in a civil clinic, he would have realized that to obtain 2 or 3 syringes in 3 months would be to be very fortunate. Maj. Laird had offered an explanation of the evidence on which he based his belief that the virus factor was not important. The cases in the clinic were from Royal Air Force, Army, Navy and civil sources and were not treated in any special order. Apart from time of attendance, they took their turn when they arrived; a syringe, therefore, might be used for a Service-woman, then for a civilian, and in the same sequence for the men. The routine was to dismantle every used syringe and wash it before putting it back into the spirit. He believed, however, that there had been a general reduction in the incidence of jaundice, not only in the Forces but also in the civil clinics, since the elaborate routine of one syringe for one patient had been adopted in the Forces. Their conclusions might not therefore be statistically significant.

In reply to Col. King's reference to desensitization, Dr. Erskine referred to the short paper which he had published in the British Medical Journal in 1939 on a series of cases of sulphonamide dermatitis. He had treated these cases with a continuation of the sulphonamide, and some were given more sulphonamide subsequently and had no further drug reaction. 'He had seen one case in which a drug rash had developed during sulphanilamide treatment, which had then been stopped; a year later the patient needed more treatment and, because of the previous reaction, he was given only half a tablet of $M$ \& B 693. Immediately severe oedema of the larynx developed. In the early days of sulphonamide treatment, a number of patients who defaulted came back after a few weeks and said that they could not attend before because they had been in hospital with " measles " or " scarlet fever". It was found that the ingestion of a single tablet would reproduce all the signs of their rash and fever. At present the 5-day treatment was the established routine and he found that sensitization was rare, but it appeared that the allergic state persisted for long periods and efforts should be made to control the condition.

With regard to demobilization of men and women from the Forces, he was sure that the problem in civil life was just as acute as that in the Forces; but, in the case of the patient who was demobilized after having had incomplete treatment, there was every reason for him to neglect the continuation of his treatment; he was going home and he would not want the neighbours to know anything about it. Therefore, there would be a risk of congenital syphilis as well as of late manifestations of syphilis. It did not seem to be sufficient to discharge the Service patient and tell him to go to a civil clinic to finish his treatment ; provision should be made for some kind of follow-up.

The point about the problem of notification which Dr. Erskine wanted to emphasize was that, if attempts were made to force people to take treatment, they would do all they could to avoid it or go to someone who would not notify them. There would always be a " black market", 


\title{
THE BRITISH JOURNAL OF ṼENEREAL DISEASES
}

if the public wanted it, and if, instead of notification, we concentrated on education and efficient propaganda, these would be much mote effective in the long run.

Dr. Mascall's remarks regarding the probability of non-specific urethritis being gonococcal were interesting, but Dr. Erskine did not think that the suggestion applied in every case. Some cases persisted for a long time and did not respond to sulphonamide treatment. Diagnosis was not only a matter of cultures ; in cases in which gonococci were not found on the film, the general appearance of the film was often unlike that seen in gonorrhoea. He agreed that Trichomonas vaginalis was probably an associated factor in some cases; even though there was a failure to find $T$. vaginalis in the male patient, it was sometimes found in his consort.

Col. King had attacked him for his remarks about jaundice. They recorded impressions in which he believed, and as such he had presented them to the meeting, but unfortunately he had not had the time or assistance necessary to carry out controlled experiments. What he had taken into account was that some patients had not had any treatment for jaundice and had taken longer to get better than did those who had received active corrective treatment. With regard to Col. King's experience of the reduced incidence of jaundice since the introduction of the Netley experiment, he submitted that other centres had experienced just the same improvement without the battery of syringes and trained personnel. He approved of the experiments to improve technique, but he felt that the results claimed ought not to be accepted until the evidence fully supported their justification.

\section{ACQUIRED SYPHILIS IN CHILDREN}

\section{THREE PROBABLE CASES}

\author{
By R. C. WOFINDEN, M.D., D.P.H. \\ Venereal Diseases Medical Officer, County Borough of Rotherham, Yorkshire
}

The majority of cases of acquired syphilis in infants and children reported in the literature are those in which the mother is non-syphilitic, the infection having been derived from some third person. Indeed, the requirements put forward by Smith for the diagnosis of acquired syphilis in infancy are as under.

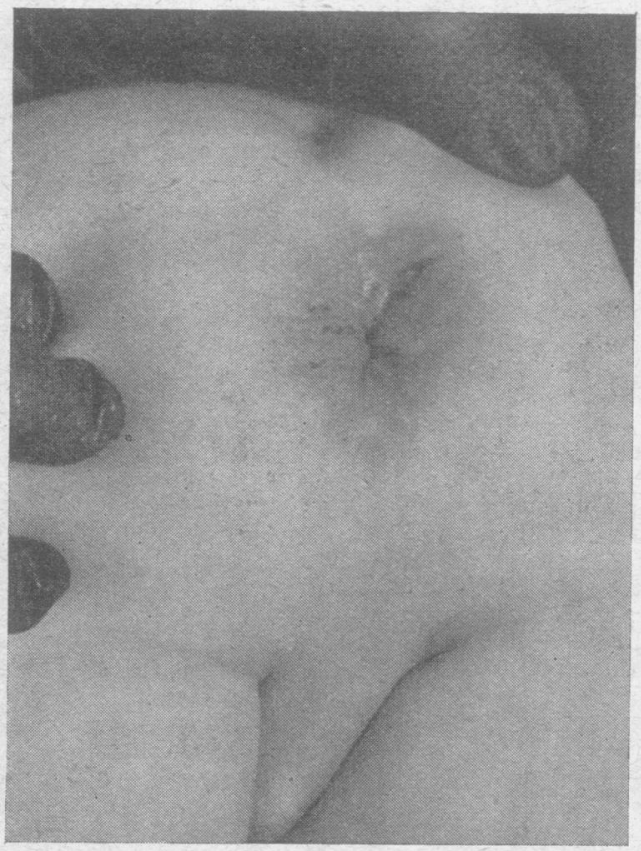

Fig. 1. Healing condylomata. The patient had been treated with acetarsol, grain 1 twice daily for 14 days.

(1) That the mother has been nonsyphilitic during her pregnancy and has never received any anti-syphilitic therapy which might have altered her serological reactions.

(2) That the child has been known to be clinically and serologically negative previously.

Neither of these criteria is fulfilled in the following three cases, but on the balance of evidence they would appear to be cases of syphilis acquired in childhood.

\section{Case 1}

On 3rd October 1944, a woman aged 21 years attended the clinic in company with her son aged 2 years 11 months and her daughter aged 1 year. The mother stated that her husband, who was in the Army, had been receiving treatment with injections for venereal disease. Six weeks prior to her visit she had noticed a vulval sore, had suffered from a sore throat and had begun also to lose her hair. The vulval sore and the sore throat had cleared up. The little boy had "a sore bottom " of one month's duration and "his hair was going thin". Extra-marital and premarital intercourse was denied. The last coitus was with her husband in May 1944 and coitus had taken place at intervals of 